\title{
An Organismal Perspective on the Evolution of Insect Societies
}

\author{
Heikki Helanterä * \\ Department of Biosciences, Centre of Excellence in Biological Interactions, University of Helsinki, Helsinki, Finland
}

Insect societies, i.e., the colonies of eusocial ants, bees, wasps, and termites, have been likened to multicellular organisms for more than a century. This framework of "superorganisms" has to date largely been used as a mechanistic description of colony functioning, or as an example of an evolutionary transition in individuality. Here I take the superorganismal view a step further, and explore what can potentially be gained if we truly accept insect societies as organisms. I suggest ways to test evolutionary theories about organismal features originally derived for solitary organisms using traits of insect societies as analogies. I explore examples such as evolution of anisogamy, sex allocation, and fertilization strategies and life histories, and point out promising directions for comparative work, and potential confounding factors in such analyses, derived from social insect studies.

OPEN ACCESS

Edited by:

Mark A. Elgar,

University of Melbourne, Australia

Reviewed by:

Rolf Kümmerli,

University of Zürich, Switzerland Joel Meunier,

Johannes Gutenberg University of Mainz, Germany Joao Alpedrinha

University of Lisbon, Portugal

*Correspondence: Heikki Helanterä heikki.helantera@helsinki.fi

Specialty section:

This article was submitted to Social Evolution,

a section of the journal

Frontiers in Ecology and Evolution

Received: 12 August 2015 Accepted: 15 January 2016 Published: 11 February 2016

Citation:

Helanterä H (2016) An Organismal Perspective on the Evolution of Insect Societies. Front. Ecol. Evol. 4:6. doi: 10.3389/fevo.2016.00006
Keywords: major transitions, individuality, organismality, social insects, inclusive fitness, anisogamy, sex allocation, life histories

\section{INTRODUCTION}

Ants, termites and many bees and wasps live in colonies with reproductive division of labor between the reproductive queen(s) and the largely sterile workers. The idea of comparing such insect societies to multicellular organisms, with queens as their germline and workers as their somatic cells, goes back to at least the works of August Weismann (1893), of the pioneering myrmecologist William Morton Wheeler (1911), and one of founding fathers of the modern evolutionary synthesis, Julian Huxley (1912), already over a century ago. The integration and homeostasis of eusocial insect colonies in traits like organization of foraging, communication, nest building and maintenance are indeed marvelous feats of cooperation and coordination that are comparable to multicellular organisms (Wilson and Sober, 1989; Seeley, 1995, 1997; Hölldobler and Wilson, 2008). While the focus of social insect studies has in the last 50 years partly shifted to intra-colonial conflicts that emphasize the balance between conflict and cooperation in insect societies instead of pure harmony and uniform cooperation (Ratnieks et al., 2006), the superorganism is still very much alive. The anatomy, physiology and genomics of superorganisms are metaphors at the heart of fruitful research programs (Seeley, 1995; Robinson et al., 2005; Johnson and Linksvayer, 2010; Linksvayer et al., 2013).

Simultaneously an overlapping discussion goes on as the general concept of organismality is being explored both in biological and philosophical literature. What units constitute adaptively evolving populations or organisms, and how such entities emerge in evolution through evolutionary transitions is investigated actively both theoretically and empirically (Maynard Smith and Szathmáry, 1995; Strassmann and Queller, 2007; Gardner and Grafen, 2009; GodfreySmith, 2009; Queller and Strassmann, 2009; Folse and Roughgarden, 2010; Bourke, 2011; Calcott and Sterelny, 2011; Clarke, 2011, 2014; Birch, 2012; Fisher et al., 2013; Kennedy et al., 2014). 
Recent authors (Gardner and Grafen, 2009; Queller and Strassmann, 2009; Folse and Roughgarden, 2010) have instead of physical integration emphasized criteria of organismality (or individuality) based on fitness alignment, lack of within-group selection and the extent of cooperation and lack of conflict. Given that insect societies are not physically as tightly connected as "traditional" organisms, I find a focus on fitness alignment natural from an insect society perspective. This fitness alignment is at its maximum when the societies consists of morphologically distinct reproductive and workers, and this is the stage when societies reach the status of (super)organisms (Wheeler, 1911; Huxley, 1912; see Boomsma and Gawne, submitted for a recent review on the uses of the term). There is a broad consensus about inclusive fitness as the framework for understanding transitions (Bourke, 2011), but it also the case that the final steps that truly bring about organismality, and complete transformation of groups of individuals into new kinds of organisms, are incompletely understood, and in need of both theoretical and empirical attention (Bourke, 2011).

In this text, I set aside the mechanistic descriptions of how superorganisms function, and the inclusive fitness factors that drive evolutionary transitions in individuality into superorganisms. I focus instead on what kind of broad evolutionary issues can potentially be tackled if we accept organismality of insect societies as a starting point, and analyze their organismal features similarly to "stereotypical" multicellular organisms. That is, if we accept that (Figure 1) instead of a society of individual insects, a social insect colony is an organism with queens and males as its germline and gametes, and non-reproductive workers as its soma. The main question I ask is what kind of superorganismal traits and patterns are useful as analogies of traits of multicellular organisms, and what kind of evolutionary predictions have potential for insight in understanding evolution of insect societies, or evolution of organismality in general.

I am not aiming for an exhaustive list of superorganismal traits to explore nor providing quantitative tests or new formal models here. I instead provide examples (Table 1) where an organismal perspective can potentially be applied, or has already been applied, and discuss the potential complications in the cross level comparisons. I will in each of the six cases very briefly summarize the main theories, discuss whether the assumptions of the general theories are likely to hold for colonies of eusocial insects as organisms, and outline the existing variation in insect societies with respect to the general theories.

Before going to the specific examples, I briefly describe the key features of insect societies as organisms (Table 1). I limit my attention to societies characterized by morphologically distinct castes, in line with the original use of the superorganism concept (Boomsma and Gawne, submitted). While current insect societies are diverse in aspects of organismality such as reproductive cycles, genetic composition and germline sequestration, comparative analyses have shown that the ancestral state was monogamy (Hughes et al., 2008), i.e., a nest started by a single queen and sperm of her single mating partner, with a life-time commitment to monogamy (Boomsma, 2009). This is comparable to a zygote formed from a sperm and an egg, and high genetic similarity among the "somatic" offspring workers guarantees selection for cooperation. In advanced eusocial insects this nuclear family has evolved into a superorganism, with a rigid morphological separation between the queen/germline and workers/soma, so that the caste of developing individuals is irreversibly fixed during larval development. The ancestral colony founding mode per se has not been formally reconstructed, but given that monogyny is the ancestral state (Hughes et al., 2008), independent founding is highly likely, which means that the founding propagules are small and there is an extremely strong bottleneck at colony foundation. In terms of Godfrey-Smith (2016) an extreme bottleneck occurs in both genetic and material terms, since only a single individual, and genomes of two individuals start the new colony. From this ancestral type in which organismality was achieved, diversification has afterwards occurred in genetic diversity of the superorganisms through both multiple mating of queens (Boomsma et al., 2009) and co-existence of multiple queens in a colony (Keller, 1993), and life cycles with dependent colony founding such as budding and fission (Cronin et al., 2013; Figure 1). This diversity is the backdrop against which I will discuss the superorganisms. I will concentrate mainly on the social Hymenoptera that are the best studied group of social insects.

\section{EXAMPLES OF SUPERORGANISMAL FEATURES AMENABLE FOR ANALYSIS}

\section{Gamete Sizes}

In multicellular organisms that reproduce sexually, gametes often come in two very different sizes, i.e., small male and large female gametes have evolved. Classic theories (Parker, 1978, 1992; Parker and Lehtonen, 2014) explain this by divergent selection, favoring small sperm on the one hand to maximize the number of fertilizations, and large eggs with resources for zygote survival and development on the other. Furthermore, theory predicts that anisogamy should be the more extreme, the larger and the more complex the individual organisms are. Since the original theories, many more potential selection pressures have been invoked, and it is clear that multiple selection pressures such as gamete limitation, gamete competition, gamete motility and avoidance of cytoplasmic conflict may lead to the same evolutionary outcomes (Cosmides and Tooby, 1981; Randerson and Hurst, 2001; Lehtonen and Kokko, 2011; Lehtonen and Parker, 2014). Below I explore whether we can apply insight from these models into what is known about males and females of social insects, the gametes of the superorganism, and whether it could provide understanding that is missed when males and females are seen in the traditional way as individuals under sex specific selection pressures.

The basic theories that predict evolution of anisogamy assume simply that large size increases survival of the zygote, and that gamete meetings are random, i.e., unaffected with traits of the gametes (Parker et al., 1972; Bulmer and Parker, 2002). Are these assumptions likely to be met when we view social insect colonies as organisms, and queens and males as their eggs 
A

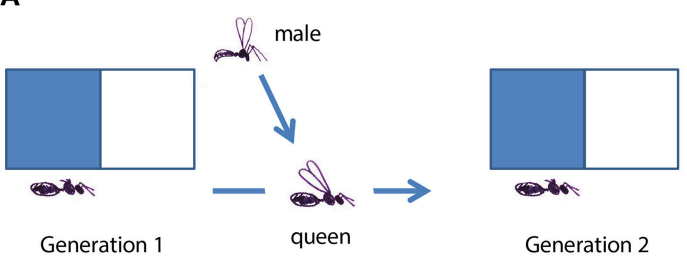

B

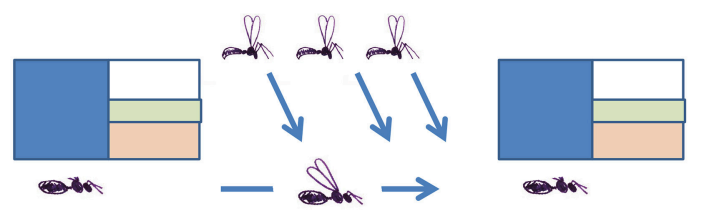

Generation 1
Generation 2

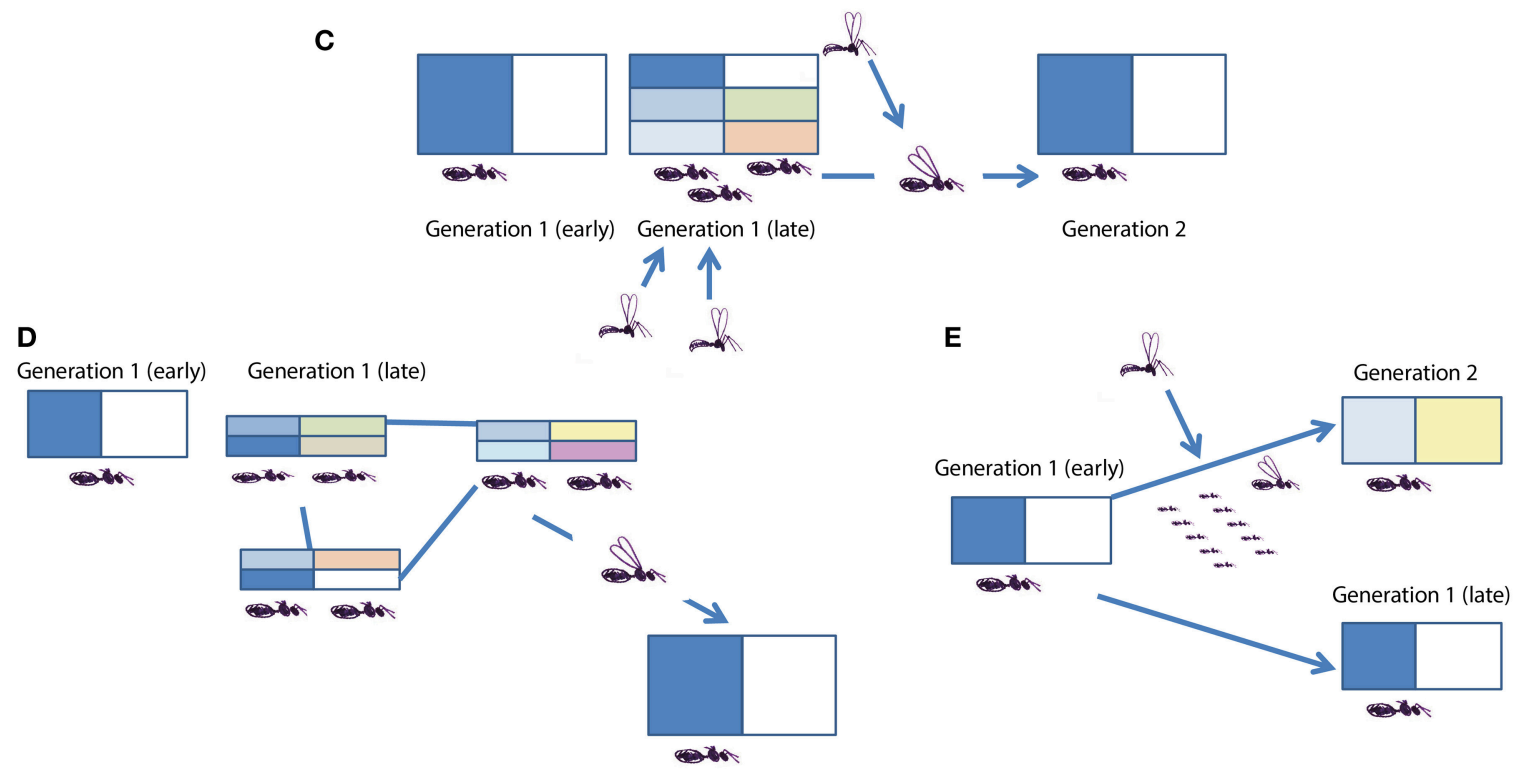

Generation 2

FIGURE 1 | Social insect life cycles. Each block denotes colony consisting of a germline(s)/queen(s) (the bottom part) and soma/workers (the top part). Arrows denote the birth of a new colony, and the move of genetic material to the colony. Colors denote genetic diversity of the colony. In reality, features of many life cycles may be combined (such as multiple mating and multiple queens). In some panels, males are left out for simplicity. (A) The ancestral state, a nuclear family society. Colonies are started independently with one singly mated queen who mates before founding a new colony. There is an extreme genetic and material bottleneck at colony foundation, and genetic material from different parent colonies is mixed at mating. Found in ants, bumble bees and vespine wasps. This is the ancestral form from which all the other life cycles have evolved, once workers have lost their totipotent options. (B) Multiple mating. Colonies are started independently with one multiply mated queen. There is a genetic (severity of which decreased by multiple mating) and strong material bottleneck at colony foundation, and genetic material from different parent colonies is mixed at mating. Compared to the ancestral situation, the colony is genetically more diverse due to several patrilines. Found in ants and vespine wasps. (C) Multiple queen (secondary polygyny). Colonies are started independently with one singly mated queen, but recruit queens that stay in their natal nest and mate in the nest, with nest mate or outside males. There is a strong genetic and material bottleneck at colony foundation, and genetic material from different parent colonies is mixed at mating. The genetic diversity of the nest increases with colony aging and growth. Found in ants. (D) Multiple queens and polydomy. Colonies are started independently with one singly mated queen or through bud nests that get separated from the other nests. Colonies recruit queens that stay in their natal nest or disperse on foot in propagules consisting of queen(s) and workers, and the propagules may or may not maintain long term contact with the mother colony. In the latter case, polydomous colonies, or even large supercolonies emerge. The bottleneck in both genetic and material terms is less severe, since both queens and workers move to new nests. New genetic material is acquired through mating, if males come from outside the colony. The genetic diversity of the nest increases with colony aging and growth. Found in ants. (E) Colony fissioning. Colonies are started dependently by propagules consisting of a queen (or queens) and a large number of workers. The material bottleneck is less severe, since both queens and workers move to new nests, severity of the genetic bottleneck depends on the number of queens moving to new nests. New genetic material is acquired through mating. Found in honeybees, stingless bees, some ants and swarm founding wasps.

and sperm, respectively? The condition that large size provides disproportionate survival benefits to zygotes (see Randerson and Hurst, 2001; Bulmer and Parker, 2002; Bulmer et al., 2002; Lehtonen and Kokko, 2011 for a more detailed discussion), is likely to apply in eusocial insects as well. Such benefits can be found through the fast growth of incipient colonies founded by large compared to small queens, a pattern likely to occur in many species of ants, bees and wasps where colonies are independently founded. Fast growing colonies minimize the vulnerable incipient colony stage when queens are without protection from the workers (Oster and Wilson, 1978; Bourke and Franks, 1995). This is especially important for claustrally founding ants that rely solely on the resources carried by the queen for rearing of the first workers, and this likely enhanced by territoriality and competition prevalent in ants (Bourke and Franks, 1995).

The other major assumption is the random fusion of gametes. When males and females are seen as the gametes, this assumption 
TABLE 1 | The discussed organismal traits and their superorganismal analogs from insect societies.

\begin{tabular}{|c|c|c|}
\hline Theme & Organism level trait & Superorganism level analog \\
\hline Anisogamy (Section Gamete Sizes) & How big are the male and female gametes produced by an organism? & $\begin{array}{l}\text { How big are the male and female sexuals } \\
\text { produced by a colony? }\end{array}$ \\
\hline Sex Allocation & $\begin{array}{l}\text { Are the two sexual functions found in separate individuals or does } \\
\text { hermaphroditism occur? If so, what is the allocation to the two functions? }\end{array}$ & $\begin{array}{l}\text { Do colonies produce both males and females? } \\
\text { If so, what is the allocation ratio? }\end{array}$ \\
\hline Fertilization Strategies & $\begin{array}{l}\text { Which gametes disperse from the parent organism, and where does } \\
\text { fertilization occur? }\end{array}$ & $\begin{array}{l}\text { Does either sex disperse before mating? Does } \\
\text { mating occur out or in the nest? }\end{array}$ \\
\hline $\begin{array}{l}\text { Life histories (Section Life History } \\
\text { Trade-Offs) }\end{array}$ & $\begin{array}{l}\text { How much does the organism invest into growth and somatic maintenance } \\
\text { vs. reproduction? }\end{array}$ & $\begin{array}{l}\text { How much does the colony invest into workers } \\
\text { and sexuals? }\end{array}$ \\
\hline $\begin{array}{l}\text { Reproductive cycles (Section } \\
\text { Reproductive Life Histories) }\end{array}$ & $\begin{array}{l}\text { Does the organism reproduce in reproduce multiple times (iteroparity) or just } \\
\text { once (semelparity) }\end{array}$ & $\begin{array}{l}\text { Does the colony produce sexuals in multiple } \\
\text { times or just once? }\end{array}$ \\
\hline $\begin{array}{l}\text { Propagule sizes (Section Evolution of } \\
\text { Propagule Size) }\end{array}$ & How much does the organism invest into a single offspring? & $\begin{array}{l}\text { How much does the colony invest into each } \\
\text { new colony (either the sexuals or the bud nest)? }\end{array}$ \\
\hline
\end{tabular}

could be violated due to sex specific selection pressures coming from e.g., mate choice by females or aggressive male-male competition. Given that aggression among males and female choice are usually thought to be absent in social insects, and competition over fertilizations scramble-like (Boomsma et al., 2005), the assumption seems to hold for many social insects. However, despite the recent advances in understanding sexual selection in social insects (Jaffé et al., 2012; Boomsma, 2013; Baer, 2015), social insect males are in general understudied, and better understanding of social insect mating systems and traits affecting male fitness is needed in order to discern whether producing a large number of small males is the best way to secure fertilizations (when fertilization success is a stochastic process), or whether there are size related benefit associated with e.g., mobility that need to be taken into account.

To my knowledge, the evolution of male and female sizes, i.e., anisogamy of the sperm and eggs of superorganisms, has not been systematically treated with large scale phylogenetically controlled data sets. The trends of the relative sizes of the sexuals have not been investigated in a phylogenetically controlled setting, but in a very broad comparison Boomsma et al. (2005) showed that females are usually larger than males (see also e.g., Pamilo and Rosengren, 1983; Boomsma, 1989) and that sexual dimorphism is larger in ants than bees and wasps, possibly due to the claustral colony founding strategies of many ants, where resources carried and metabolized by the non-foraging foundress queens are essential for survival of the incipient nest. However, the sizes of queens seem evolutionarily highly flexible. Decreases in queens size have occurred especially in multiple queen colonies that have lost independent colony founding, and queen number may vary even within species (Rüppell et al., 1998; Heinze and Keller, 2000; Sundström et al., 2005; Steiner et al., 2006; Boulay et al., 2014).

Based on the above, I suggest some potential comparative tests. First is obviously the predicted positive correlation with colony size and worker caste diversity as possible measures of organismal complexity and the extent of anisogamy. Second, it should be investigated whether either species with non-claustral or semi-claustral (Brown and Bonhoeffer, 2003), or nonindependent founding have smaller queens than claustrally, or in general independently founding species when the phylogeny, concurrent changes in male size, and idiosyncratic social insect features like secondary polygyny (Boomsma et al., 2014), queen selfishness (Nonacs and Tobin, 1992), social parasitism (Buschinger, 2009) and pleometrotic colony founding (where queens found colonies together, Bourke and Franks, 1995) are accounted for. Also termites could be an interesting point of comparison here, since in termites both sexes contribute to colony founding, which should favor also large male sizes, i.e., lack of anisogamy at the superorganismal level. Third, it should be tested whether potentially high male-male competition in species with extremely male biased investment sex ratios, or bees and wasps with territory defending males (Boomsma et al., 2005) is linked to a decrease in sexual dimorphism, i.e., a reversal in the anisogamy trend at the superorganism level. Furthermore, all of this data needs to be interpreted in the light of genetic data describing the relevant mating group sizes that measure the extent of potential gamete limitation (Lehtonen and Kokko, 2011). Finally, a feature that may affect size dimorphism in ways that are not relevant outside superorganisms, is multiple mating by social insect males (Boomsma et al., 2005). To my knowledge sperm cells that would fertilize multiple eggs don't exist, and this may affect anisogamy of superorganisms in ways that are unknown yet.

In summary for this section, I see anisogamy as a highly potential superorganismal study topic. For social insect studies, it both provides an alternative conceptualization for males and females, and brings new questions and approaches into an understudied field. For studies of anisogamy in general, it provides independent novel hypothesis tests to assess the generality of patterns. Life histories of social insects could provide insight to the costs and benefits of different gamete sizes in a novel way.

\section{Sex Allocation}

Sexually reproducing multicellular organisms invest either in one sexual function only (dioecious or gonochoristic) or in both sexual functions simultaneously (hermaphroditic). The theories that explain sex allocation and the existence of separate sexes are well developed and diverse (Charnov, 1982; West, 2009), and are based on the frequency dependent relative fitness returns for investment into different sexes, and how they are affected by population structures that determine how the two sexes compete 
over mates and resources. I will first deal with evolution of separate sexes in insect societies, and then with sex allocation when insects societies are seen as simultaneous hermaphrodites.

\section{Evolution of Separate Sexes}

Evolution of separate sexes from a hermaphroditic ancestral state (the ancestral state in social insects) is predicted to occur when fitness returns from investing into one sex are non-linear, so that $100 \%$ allocation to the sex that has increasing returns from investment is predicted. Alternatively, $100 \%$ investment into one sex is predicted if there are large baseline costs (such as sex specific tissues for gamete production) before any resources can be allocated to one of the sexual functions. Hermaphroditism, in contrast, is expected when baseline costs are low, and/or fitness return curves saturating, i.e., highest fitness return are expected at intermediate allocations (Charnov, 1982).

Given that in haplodiploid social insects the sex of a developing individual is determined by the fertilization of the egg, large baseline costs of producing one sex only are unlikely, since the only costs are the machinery to regulate egg fertilization. The ability to not fertilize eggs (i.e., produce males) is not likely to be very costly, and losing it would not be highly beneficial. Furthermore, the ability to fertilize eggs is necessary if the queen is to produce any female workers, so loss of this ability (which would translate into the loss of female function) is not a viable option. The other route to separate sexes, accelerating fitness returns of producing one sex, have never been demonstrated in insect societies. It has been suggested that manipulative strategies related to queen worker conflict over sex allocation could in some circumstances drive such fitness functions (Reuter et al., 2004; Helms et al., 2005), but this remains unexplored in social insects.

Sex ratios in social insects have been under intense studies in the framework of within colony conflicts, and are fairly well understood both theoretically and mechanistically (Boomsma and Grafen, 1990, 1991; Meunier et al., 2008; Helanterä and Ratnieks, 2009; Kümmerli and Keller, 2009). Split sex ratios, which can be seen as the superorganism equivalent of separate sexes, have been observed in many species. These patterns have been largely explained by scenarios invoking queen worker conflict over sex allocation, and variation in either relatedness asymmetries, or variation in the relative power of the conflict parties (Meunier et al., 2008; Helanterä and Ratnieks, 2009; Kümmerli and Keller, 2009), and organismal theories of evolution of separate sexes have not been invoked as an explanation. An exception is the harvester ant Pogonomyrmex occidentalis, where colonies are treated as organisms when explaining the absence of split sex ratios, through careful assessment of the sex-specific fitness return functions (Wiernasz and Cole, 2009). In general, I argue that evolution of separate sexes in superorganisms is unlikely, in line with the theoretical logic explained above. First, baseline costs are likely to be minimal. Second, there is no clear reason why accelerating returns for one sex would arise, outside of scenarios invoking within colony conflict. Third, split sex ratios do not constitute a permanent loss of the ability to produce one sex at a colony level. Even if the sex ratios would be fairly stable over the colony lifetime, a complete loss of one sexual function is an unlikely scenario. Thus, it seems justified to assume that superorganismal insect societies are likely to retain their hermaphrodite life style, and discuss split sex ratios under the general topic of sex allocation variation, rather than evolution of separate sexes.

\section{Sex Allocation in Simultaneous Hermaphrodites}

Assuming that strictly speaking separate sexes, i.e., colonies that would have permanently lost the ability to produce either sex, have not evolved in social insects, I turn next to sex allocation of colonies seen as simultaneous hermaphrodites. Given that sex ratios of social Hymenoptera are a showcase example of adaptation (West, 2009), the question we need to ask is whether we gain new insight into sex allocation of insect societies if we draw inspiration from theories that explain allocation to different sexual functions in hermaphrodites?

Sex allocation theory, which I will here present in a very crude outline (based on Charnov, 1982; West, 2009), predicts that at evolutionary equilibrium, the frequency dependent fitness returns per unit of investment should be equal for the two functions. These payoffs are shaped both by ecological and internal features that determine how efficiently resources can be used to produce offspring of either sex, whether there is a maximum number of individuals of either sex that can be reared, how offspring quality and size are correlated in each sex, and by population level features that determine which sex competes for what, and at what spatial scale. Sex specific competition can occur over matings or resources such as nesting sites or gametes, the latter thought to be especially crucial for simultaneous hermaphrodites (Schärer, 2009). In general, the sex where the competition is more intense among kin, or more locally concentrated in small groups, should be produced in smaller numbers, irrespective whether the perspective is on competition among gametes, or individuals that produce the gametes (West, 2009).

With respect to the assumptions of sex allocation theories for simultaneous hermaphrodites, insect societies look like a promising study system. This is because many of the problems for assessing resource allocation in the traditional study organisms (Schärer, 2009) do not seem to apply. First, the allocation is easy to measure through counts and weights of the sexuals produced (but see Boomsma, 1989; Boomsma and Nachman, 2002). Furthermore, as egg fertilization determines the sex, there are no separate costs into gametes (dynamic costs) and the sex specific reproductive tissues of the parent organism (fixed costs), and investment into the two sexes is predominantly simultaneous. Finally, as the types of resources needed for the production of the two sexes should be fairly similar (but see Boomsma, 1989; Boomsma and Nachman, 2002; Wiernasz and Cole, 2009), the trade-off between the two sexes is straightforward. In this respect social insects do have potential as a test bed for hermaphroditic sex allocation theories.

However, it is difficult to see at first what added explanatory power the hermaphrodite view would offer for social insect studies, given the prominence of explaining sex ratio variation within species by kin structure variation and conflicts (Chapuisat and Keller, 1999; Ratnieks et al., 2006; Meunier et al., 2008). In addition to queen-worker conflict as an explanation of sex ratios, 
also the extent of within-sex competition over either mates or resources may explain considerable parts of the variation within species (Meunier et al., 2008), but such patterns are consistent with either view-i.e., can be explained through theories that take a perspective of either the organism and its gametes, and the sizes of local mating groups where the gametes compete, or numbers of males and females produced and their competition.

In addition to explaining proportions of within species variation in some cases (Fournier et al., 2003; Kümmerli et al., 2005; Meunier et al., 2008), a local competition angle could explain the among species variation in average sex ratios of population. The predominantly female biased ratios of especially ants have traditionally been explained as worker control of sex allocation (Trivers and Hare, 1976; Bourke and Franks, 1995), and this view has extensive support from more detailed analyses (Sundström et al., 1996; Chapuisat et al., 1997; Kümmerli and Keller, 2009), although worker control is not universal (Helms, 1999; Helms et al., 2000; Passera et al., 2001). In an alternative superorganismal treatment, population structures and sex biased dispersal would be the key factors that explain sex allocation. Local competition based explanation for the average sex ratios, originally outlined by Alexander and Sherman (1977) have largely been dismissed since panmixia through mating flights is thought to be common in social insects (Bourke and Franks, 1995), and invoking local competition has usually not been necessary for explaining sex ratios (but see e.g., Fournier et al., 2003; Kümmerli et al., 2005; Meunier et al., 2008 for examples of local resource competition). Furthermore, where sex specific population structures have been shown, they're confounded with factors like propagule sizes and high genetic diversity of the nests (Ross et al., 1997, 1999; Gyllenstrand and Seppä, 2003; Seppä et al., 2004; Gyllenstrand et al., 2005), which makes interpretation of sex allocation patterns in the light of local mate or resource (or gamete) competition theory for hermaphrodites challenging.

On the other hand, detailed population genetic investigations about sex biased dispersal and the genetic composition of the actual mating flights (i.e., effective sizes of mating groups) are not numerous enough for completely rejecting a role for local competition, Specifically, even insects with life cycles usually associated with panmixia, i.e., single queen per nest and mating flights may have quite strong population structures and sex biased dispersal (Sundström et al., 2003). Thus, local competition theories might in some cases have been dismissed prematurely as explanations of among species variation. Keeping in mind that competition over mates or resources affects optimal sex ratios of both queens and workers, systematic comparisons of average levels of female bias and the genetic structures of mating flights across species could prove interesting, and add even further layers into our understanding of social insect sex ratios.

In summary for this section, it is a considerable task to improve the advanced understanding of social insect sex ratios already achieved. In order for an organismal perspective to achieve this, both extensive comparative analyses, informed with detailed population genetic data about mating groups, and theoretical models that simultaneously consider numerical sex ratios, mating group sizes and evolution of queen and male sizes would probably be needed.

\section{Fertilization Strategies}

Organisms also vary widely in how the fertilization occurs, i.e., whether both types of gametes are released into the environment (broadcast spawning or external fertilization), or whether fertilization occurs internally through sperm casting (i.e., that sperm disperse, eggs don't) or mating (Henshaw et al., 2014). If insect societies are seen as hermaphroditic sessile organisms, at least one type of gametes, queens or males, needs to leave the colony for a non-selfing fertilization to take place, and direct mating with internal fertilization between two superorganisms is not an option. Selfing is possible if a colony produces both sexes and they mate in the natal nest. The most relevant theory and data thus comes from either plants, or sessile marine invertebrates that face similar demands.

In plants, sperm/pollen casting is dominant, although the evolutionary reasons for absence of cases where both gametes disperse are not well understood (Fromhage and Kokko, 2010; Henshaw et al., 2014). Patterns of variation described in marine invertebrates show that in general, sperm casting goes with small size (Strathmann and Strathmann, 1982), sperm casters are predominantly hermaphrodites and have larger offspring than broadcast spawners (Kupriyanova et al., 2001). Recent theory explains this in the light of local gamete competition (Henshaw et al., 2014): if gamete availability is limiting for reproduction, large individuals should release both gametes if their fecundity increases faster than sperm availability for retained gametes, and gamete limitation causes diminishing returns for female production, favoring hermaphroditism.

Secondary polygyny is the closest insect society equivalent of sperm casting. Young queens mate locally and are recruited back to their natal colonies. Such life histories have evolved repeatedly in ants, and are phylogenetically very flexible (Sundström et al., 2005; Cronin et al., 2013; Boulay et al., 2014), but are absent or rare in other social Hymenoptera and termites (Boomsma et al., 2014). Secondary polygyny is often associated with large colony size (Rosengren et al., 1993; Boulay et al., 2014), suggesting an opposite pattern to marine invertebrates. In contrast, a correlation between large offspring size and sperm casting is possible, similarly to marine invertebrates: many polygynous systems have life cycles (Debout et al., 2007), where new colonies are founded through large propagules containing both queens and workers (see below), which constitutes large offspring size at the superorganism level.

Thus, insect societies do not at least fully align with patterns from marine invertebrates. This could be due to idiosyncratic features of insect societies as organisms. First, it is debatable how comparable secondary polygyny is to sperm casting fertilization in multicellular organisms. If queens remain in their natal nest, or form a bud nest that stays connected to the mother colony, there is movement of genetic material between superorganisms, but no new organism is born, and the analogy to sperm casting becomes unclear. A new colony organism is born, and the analogy holds better, only if the bud or fission nest does not remain in contact with the mother colony. Note that the same proviso applies to mating in the nest as an analog of selfing. Second, gamete limitation might not be an important selection pressure for many social insects since intra-nest mating is common in polygynous 
social insects (the model of Henshaw et al., 2014 assumed absence of selfing), intra-nest mating might not even result in significant inbreeding in genetically diverse societies, and even a complete lack of mating would not prevent a queen from reproduction since they can still produce males. Furthermore, as all social insect nests are potentially simultaneous hermaphrodites, no correlations can be found with respect to hermaphroditism and fertilization strategies. And finally, as above, the internal genetic diversity of the superorganisms may co-vary with population structures and strongly affect the optimal traits (see references above), especially since evolution of polydomy is often preceded by evolution polygyny and increased genetic diversity (Cronin et al., 2013).

Clearly insect societies have several features that make direct analogies to traditional organisms challenging. Before comparative analyses can be used to test for commonalities across levels of organismality, theoretical work is needed to clearly outline how social insect features such as within colony conflicts over dispersal and queen recruitment, and the underlying kin structure variation affect the predicted relationships between life-history traits, population structures and fertilization modes.

\section{Life History Trade-Offs}

Evolution of colony life cycles is an area where an organismal perspective has already been applied early on. Investment into sexuals and workers has been treated explicitly as a trade-off between reproduction and growth/maintenance, and analyzed in an optimality framework already in the seminal book of Oster and Wilson (1978). Optimality arguments at the superorganism level, i.e., somatic vs. reproductive allocation, are invoked to explain the predominance of bang-bang reproduction strategies both in the life cycles of annual colonies (common in e.g., bumble bees and yellowjacket wasps) and within seasons in perennial colonies (prevalent in ants, honey bees, and stingless bees), and the delay of first reproduction in societies with high survival.

The trade-off between reproduction and somatic growth and maintenance is easy to conceptualize at the superorganismal level as the mutually exclusive investment into workers and sexuals (Table 1). Despite the analogy, comprehensive studies of colony level life-histories remain few (but see e.g., Cole, 2009; Ingram et al., 2013), and the life-span reproduction trade-offs have not been intensely studied at the colony level. The superorganismal perspective is further justified by the observation that at the lower level of individuals within colonies social insects break the tradeoffs that apply to solitary organisms. The reproduction/life-span trade-off is absent in comparisons among castes, since queens are able to enjoy both longer life spans and higher reproductive output compared to workers (Keller and Genoud, 1997), much like germline cells compared to somatic cells (Boomsma et al., 2014). Furthermore, even among queens the usual trade-offs do not seem to apply, as recent studies have shown that high reproductive success does not compromise life-spans of the queens (Heinze and Schrempf, 2012; Heinze et al., 2013). Social insect queens might not suffer from reproductive trade-offs similarly to solitary organisms, since the costs of reproduction are mostly carried by the workers who take care of the brood and maintain colony homeostasis. Workers are probably also largely in power of the allocation strategy and buffer the queen from external mortality, thus allowing selection for long life spans.

Given the above, the evolution of life spans of the individuals within societies is comparable to long lived germline cells and short lived and dispensable somatic cells (Boomsma et al., 2014). Long queen life span is under strong colony level selection and there are only very narrow opportunities for conflict. This is especially clear in monogynous species where queen life span equals colony life span (Keller and Genoud, 1997), and within organism conflict is small, as expected from a system that has gone through a transition toward superorganismality already. Furthermore, the life span divergence between queens and workers increases with colony size (Kramer and Schaible, 2013; although polygyny or dependent colony founding may reverse this trend (Keller and Genoud, 1997; Schrempf et al., 2011; Boomsma et al., 2014), presumably reflecting the fact that larger colonies are usually more complex, have resolved many of the conflicts associated with genetic diversity within colonies, and are thus more advanced in the extent of the evolutionary transition in individuality.

Life-history trade-offs are perhaps the case where an organismal perspective is the easiest applied to insect societies (Oster and Wilson, 1978; Bourke and Franks, 1995). While comparative data from natural populations is rare and extremely labor-intensive to achieve, and unavailable apart from a few model systems (Cole, 2009; Gordon, 2010), there is potential in experimentally accessible colonies with shorter life spans (Heinze and Schrempf, 2012; Heinze et al., 2013). Even if social insect life histories have been described in an organismal light for almost 40 years, there is much unexplored potential to experimentally study how life-history trade-offs that regulate e.g., colony aging evolve at the superorganismal level.

\section{Reproductive Life Histories}

In addition to reproductive allocation within a life history, we can also apply an organismal perspective on the lifehistories themselves, i.e., whether colonies reproduce only once (semelparity), or repeatedly (iteroparity). This is also an area where the organismal perspective has been assumed in earlier treatments, and my discussion is largely based on Bourke and Franks (1995). General theories predict that deviations from a single reproductive event should only evolve when juvenile mortality is high and/or highly variable compared to adult mortality (Charlesworth, 1994), otherwise reproducing fast and early is more beneficial (Stearns, 1992).

On first intuition, it would seem that many social insects fit the predictions for evolution of iteroparous life. Colonies with independent founding are vulnerable during the phase when solitary queens mate and found the colony, but are protected against external threats once the worker force has grown enough. Thus, colony mortality is at the highest when they are young. In line with this logic, iteroparous reproduction is the rule in ants and termites. In ants, the bet-hedging benefits of iteroparity are amplified by highly competitive "gap dynamics" environments. Similarly to canopy trees (Stearns and Crandall, 1981) whose dispersing seeds need to find a tree-fall gap to survive, a foundress queen has to find a gap in the matrix of existing ant territories. If 
such gaps occur rarely and randomly, the bet hedging iteroparous life may more often be favorable in ants than in the less territorial flying social insects (Bourke and Franks, 1995; Boomsma et al., 2014).

In social bees and wasps the situation is more variable. Bumble bees, yellowjacket wasps, and hornets (with the exception of Provespa Ross and Matthews, 1991) live semelparous, annual life cycles, even if their solitary overwintering and independent colony founding behavior at first sight would fit the iteroparous assumptions of high juvenile mortality and higher adult survival when worker force is fully developed and the queen well protected. This at first sight enigmatic persistence of semelparity could be explained if the adult nest survival in bumblebees and wasps is not as high, and early mortality not as extreme as in ants (Cronin et al., 2013), possibly due to lack of territoriality induced mortality of foundresses, and vulnerable nest structures (Boomsma et al., 2014). Also internal conflicts, such as matricide by workers (Bourke, 1994; Loope, 2015), may play a role in determining colony life cycles.

Honeybees and stingless bees (and swarm-founding wasps whose organismality is questionable due to lack of strict morphological castes) are iteroparous (Bourke and Franks, 1995; Boomsma et al., 2014). In their societies reproducing by fission, the adaptive value of iteroparity is more difficult to see than in ants, as the mortality of young societies is not as low as in independently founding species, and colony and queen life spans are not as high as in ants (Boomsma et al., 2014). The number of independent origins of such life-histories is currently unknown (two separate origins have been shown for corbiculate bees Cardinal et al., 2010), but is likely to be small, and thus comparative studies may find it difficult to tease apart confounding factors such as propagule sizes (see below) and evolution of fissioning reproduction.

In summary of this section, it seems that scarcity of both life history data and phylogenetically informative contrasts makes it difficult to interpret the current patterns in an adaptive light, and to tease apart the different explanations. Given the lack of variation in life cycles within all major groups except ants, and the seemingly enigmatic life histories of bees, perhaps the right question to ask is whether there are important constraints that prevent life cycles from diversifying?

\section{Evolution of Propagule Size}

In addition to the reproductive schedules, life cycles of superorganisms vary widely in the level of investment into the propagules from which the new colonies start (in addition to the variation in size of the egg/foundress queen discussed above). The ancestral state is a single individual mated queen propagule, which also constitutes an extreme genetic bottleneck. However, evolution of increased propagule size has occurred repeatedly (Debout et al., 2007; Cronin et al., 2013). Large investment in propagules that start new societies comes in two forms. Honeybees, stingless bees and swarm founding wasps and some ants reproduce by colony fission (Cronin et al., 2013; Figure 1) where a large proportion of the worker force leaves the nest with queens, i.e., the propagule is up to half the size of the organism, reminiscent of reproduction by division in microbes, or breaking off of ramets from a vegetatively reproducing plant. It might be tempting to compare asexual reproductive events from unicellular, multicellular and superorganismal levels directly. However, such reproductive events in superorganisms are more complicated than simple splitting of the organism, since exchange of genetic material between colonies is involved, so fissioning cannot be straightforwardly conceptualized as asexual reproduction.

Budding in ants (see above as well) on the other hand may either be conceptualized as growth [if the bud nest remains in contact with the mother nest as a part of a polydomous colony (Rosengren and Pamilo, 1983; Debout et al., 2007; Ellis and Robinson, 2014)] or reproduction, when the contact between nests is lost after dispersal. In such cases the definitions of individuals become problematic, since the border between growth and reproduction is difficult to define, similarly to plants with vegetative reproduction (Tuomi and Vuorisalo, 1989; Clarke, 2011).

These diverse phenomena can be analyzed under the common framework of propagule sizes (largely following the discussion in Bourke and Franks, 1995). First, same factors that select for iteroparity should select, all else being equal, for large propagule sizes, i.e., dependent colony founding where workers accompany founding queens. The evolutionary origins of large propagule sizes in bees and wasps (fissioning only, no polydomy has been described outside ants) are few, making adaptive explanations difficult to study formally with comparative methods (Cronin et al., 2013). In ants the situation is more amenable for comparative analyses, since dependent colony founding has evolved repeatedly. Formal comparative analyses are lacking, but the likely selective reasons include habitat saturation, nestsite instability and in general difficult conditions for founding new nests (Debout et al., 2007; Cronin et al., 2013). However, the evolution of dependent founding in ants is usually associated with polygyny (Boomsma et al., 2014), with army ants being one of the notable exceptions, and it is unclear which of these selective factors apply in non-polygynous species, and what is the role of genetic diversity and within colony conflicts over dispersal in the evolution of dependent colony founding. In a review on ant polydomy, no clear ecological syndrome associated with polydomy was found (Debout et al., 2007), and the polydomous and polygynous life cycles may be selected for under very different ecological conditions such as high disturbance and very stable habitats (Helanterä et al., 2009). Furthermore, when interpreting patterns of dependent colony founding the increased kin competition caused by short distance dispersal on foot is a factor counterbalancing the benefits of increased survival at colony founding (Boomsma et al., 2014).

Thus, future formal analysis of propagule size evolution should be interpreted in the light of the relevant population genetic structures and variation in genetic diversity within nests. Similarly to fertilization modes, the fit of organismal analogies is complicated by idiosyncratic details of insect society life histories, and the presence of internal conflicts. Careful modeling, with underlying assumptions grounded in natural history of the relevant systems, should reveal the most important shared processes and idiosyncrasies that are needed to guide the empirical tests and comparisons across different levels of organismality. 


\section{CONCLUSIONS}

The above can be viewed from several different viewpoints. First, it offers us a potential complementary conceptualization of the evolution of insect societies, a window into understanding diversity of social insect life histories and reproductive strategies in a new light, e.g., when male and queen sizes and sex allocation are interpreted in the light of gamete competition theories. Second, it highlights testing grounds for broad comparative predictions across levels of organismality, e.g., when shared life history trade-offs are analyzed in solitary organisms and superorganisms. Furthermore, it demonstrates the roles of general processes that transcend levels of organization on the one hand, and idiosyncratic details on the other, when e.g., comparisons of fertilization modes or propagule sizes across levels of organismality run into problems. Ideally, as a result of such analyses information would flow both to social insect studies, and studies of organisms in general, and I claim that in addition to successful analogies also carefully analyzing the reasons of failed analogies will prove informative.

The traits I explored reveal diversity in how well organismal analogs work. This is an important conclusion for organismality-whether insect societies are the best seen as adaptive units at the colony level, or as fields of conflict and within group selection among colony members depends not only on whether we are investigating taxa with facultative or obligate eusociality, but also on the trait investigated. Achieving organismality is not a uniform process, and the balance of individual and colony level selective forces depends on the trait in question. Evolution of life-history trade-offs seem easier to conceptualize as organismal traits, evolving like group-selected adaptations, whereas evolution of e.g., sex allocation and fertilization modes are heavily confounded with factors where conflicts among individuals over e.g., sex allocation preferences and dispersal behavior still play crucial roles. Clearly these reflect the differences in the extent to which superorganismal traits evolve as predicted for organisms, and in what respects insect societies can be seen as "Darwinian populations" (Godfrey-Smith, 2009) at the superorganism, but not individual level.

The cases where analogies look complicated to apply suggest that models derived for solitary organisms need to be modified for social insects before assessing whether same factors emerge as crucial across levels of organismality, and older models are at least not in all cases directly suitable for superorganisms. The confounding factors such as genetic diversity and within colony conflict are the key for empirical tests of the theories. As these topics have been the focus of both theoretical and empirical social insect science for decades, and indeed represent some of the key successes of inclusive fitness logic (Abbot et al., 2011), there should be a lot of relevant data out there that needs to be employed to systematic comparative tests to tease apart general and idiosyncratic explanations.

In the light of the above, the internal genetic diversity of superorganisms is a key feature in understanding them. Insect societies are probably unique organisms in the extent of variation in genetic diversity, and also in how well we understand the causes and consequences of the genetic diversity such as variation in mate and queen numbers (Crozier and Pamilo, 1996). Variation in genetic diversity is not of course limited to superorganisms, since both mosaicism and chimerism occur in many groups of organisms (Pineda-Krch and Lehtilä, 2004; Nonacs and Kapheim, 2007; Folse and Roughgarden, 2010). The resistance toward intra-organismal genetic diversity has sometimes been seen as a defining feature of evolutionary transition. While exclusion of outsiders, and group cohesion are certainly one of the key features of the emergence of successful insect societies as an evolutionary transition (Bourke, 2011), the picture is clearly more complex as genetic diversity can evolve once organismality has been reached, with complex consequences for organismal features. Social insects should be a showcase for the evolution and consequences for genetic heterogeneity within organisms.

Social insects have been highly successful study organisms in understanding the role of high kinship in major transitions (monogamy hypothesis Boomsma, 2007, 2009; Hughes et al., 2008), and the factors that determine the balance of cooperation and conflicts in societies (Ratnieks et al., 2006), but I claim that there is potential for even further lessons for understanding social insects and understanding evolution of organismality if we try to analyze, not just describe, insect societies as organisms-from both successes and failures of the organismal analogies. Systematic data gathering of life-history features of superorganisms is crucial for such advances, as has been recognized already a while ago (Tschinkel, 1991). Comparative studies are shedding light on social evolution in numerous contexts, such as sex allocation (West et al., 2001), intra-group conflict (Wenseleers and Ratnieks, 2006; Schultner et al., 2014), and the role of kinship (Hughes et al., 2008; Duffy and Macdonald, 2010; Fisher et al., 2013) and preadaptation (Ross et al., 2013) in evolution of eusociality and cooperative breeding (Cornwallis et al., 2010; Lukas and Clutton-Brock, 2012), and insect societies have high further potential in this area. Especially the diversity found in ants offers new independent tests for the association of e.g., reproductive traits such gamete sizes and sex ratios and life history variables such as colony sizes and founding modes.

\section{AUTHOR CONTRIBUTIONS}

The author confirms being the sole contributor of this work and approved it for publication.

\section{FUNDING}

The author was funded by the Academy of Finland (grant 135970 to HH, grant 252411 to Centre of Excellence in Biological Interactions) and the Kone Foundation.

\section{ACKNOWLEDGMENTS}

I thank the referees, M. Elgar and J.J. Boomsma for constructive criticism and insightful comments. 


\section{REFERENCES}

Abbot, P., Abe, J., Alcock, J., Alizon, S., Alpedrinha, J. C., Andersson, M., et al. (2011). Inclusive fitness theory and eusociality. Nature 471, E1-E4. doi: 10.1038 /nature09831

Alexander, R. D., and Sherman, P. W. (1977). Local mate competition and parental investment in social insects. Science 196, 494-500. doi: $10.1126 /$ science.196.4289.494

Baer, B. (2015). "Female choice in social insects," in Cryptic Female Choice in Arthropods, eds A. V. Peretti and A. Aisenberg (Springer), 461-477. doi: 10.1007/978-3-319-17894-3_17

Birch, J. (2012). Collective action in the fraternal transitions. Biol. Philos. 27, 363-380. doi: 10.1007/s10539-012-9312-8

Boomsma, J. (1989). Sex-investment ratios in ants: has female bias been systematically overestimated? Am. Nat. 133, 517-532. doi: 10.1086/284933

Boomsma, J. J. (2007). Kin selection versus sexual selection: why the ends do not meet. Curr. Biol. 17, R673-R683. doi: 10.1016/j.cub.2007.06.033

Boomsma, J. J. (2009). Lifetime monogamy and the evolution of eusociality. Philos. Trans. R. Soc. B Biol. Sci. 364, 3191-3207. doi: 10.1098/rstb.2009.0101

Boomsma, J. J. (2013). Beyond promiscuity: mate-choice commitments in social breeding. Philos. Trans. R. Soc. B Biol. Sci. 368:20120050. doi: $10.1098 /$ rstb. 2012.0050

Boomsma, J. J., Baer, B., and Heinze, J. (2005). The evolution of male traits in social insects. Annu. Rev. Entomol. 50, 395-420. doi: 10.1146/annurev.ento.50.071803.130416

Boomsma, J. J., and Grafen, A. (1990). Intraspecific variation in ant sex-ratios and the Trivers-Hare hypothesis. Evolution 44, 1026-1034. doi: 10.2307/2409564

Boomsma, J. J., and Grafen, A. (1991). Colony-level sex-ratio selection in the eusocial Hymenoptera. J. Evol. Biol. 4, 383-407. doi: 10.1046/j.14209101.1991.4030383.x

Boomsma, J. J., Huszár, D. B., and Pedersen, J. S. (2014). The evolution of multiqueen breeding in eusocial lineages with permanent physically differentiated castes. Anim. Behav. 92, 241-252. doi: 10.1016/j.anbehav.2014.03.005

Boomsma, J. J., Kronauer, D. J., and Pedersen, J. (2009). “The evolution of social insect mating systems," in Organization of Insect Societies. From Genome to Sociocomplexity, eds J. Gadau and J. H. Fewell (Cambridge, MA: Harvard University Press), 3-25.

Boomsma, J. J., and Nachman, G. (2002). "Analysis of sex ratios in social insects," in Sex Ratios: Concepts and Research Methods, ed I. C. W. Hardy (Cambridge: Cambridge University Press), 93-111.

Boulay, R., Arnan, X., Cerdá, X., and Retana, J. (2014). The ecological benefits of larger colony size may promote polygyny in ants. J. Evol. Biol. 27, 2856-2863. doi: $10.1111 /$ jeb.12515

Bourke, A. F. (1994). Worker matricide in social bees and wasps. J. Theor. Biol. 167, 283-292. doi: 10.1006/jtbi.1994.1070

Bourke, A. F. G. (2011). Principles of Social Evolution. Oxford, UK: Oxford University Press. doi: 10.1093/acprof:oso/9780199231157.001.0001

Bourke, A. F. G., and Franks, N. R. (1995). Social Evolution in Ants. Princeton, NJ: Princeton University Press.

Brown, M. J. F., and Bonhoeffer, S. (2003). On the evolution of claustral colony founding in ants. Evol. Ecol. Res. 5, 305-313.

Bulmer, M. G., Luttikhuizen, P. C., and Parker, G. A. (2002). Survival and anisogamy. Trends Ecol. Evol. 17, 357-358. doi: 10.1016/S0169-5347(02) 02537-5

Bulmer, M. G., and Parker, G. A. (2002). The evolution of anisogamy: a game-theoretic approach. Proc. R. Soc. B Biol. Sci. 269, 2381-2388. doi: 10.1098/rspb.2002.2161

Buschinger, A. (2009). Social parasitism among ants: a review (Hymenoptera: Formicidae). Myrmecol. News 12, 219-235.

Calcott, B., and Sterelny, K. (2011). The Major Transitions in Evolution Revisited. Cambridge, MA: MIT Press. doi: 10.7551/mitpress/9780262015240.001.0001

Cardinal, S., Straka, J., and Danforth, B. N. (2010). Comprehensive phylogeny of apid bees reveals the evolutionary origins and antiquity of cleptoparasitism. Proc. Natl. Acad. Sci. U.S.A. 107, 16207-16211. doi: 10.1073/pnas.1006299107

Chapuisat, M., and Keller, L. (1999). Testing kin selection with sex allocation data in eusocial Hymenoptera. Heredity 82, 473-478. doi: 10.1038/sj.hdy. 6885340
Chapuisat, M., Sundstrom, L., and Keller, L. (1997). Sex-ratio regulation: the economics of fratricide in ants. Proc. R. Soc. Lond. B Biol. Sci. 264, 1255-1260. doi: 10.1098/rspb.1997.0173

Charlesworth, B. (1994). Evolution in Age-Structured Populations. Cambridge: Cambridge University Press. doi: 10.1017/CBO9780511525711

Charnov, E. L. (1982). The Theory of Sex Allocation. Princeton, NJ: Princeton University Press.

Clarke, E. (2011). "Plant individuality and multilevel selection theory," in The Major Transitions in Evolution Revisited, eds B. Calcott and K. Sterelny (Cambridge, MA: MIT Press), 227-250.

Clarke, E. (2014). Origins of evolutionary transitions. J. Biosci. 39, 303-317. doi: $10.1007 / \mathrm{s} 12038-013-9375-\mathrm{y}$

Cole, B. J. (2009). "The ecological setting of social evolution: the demography of ant populations," in Organization of Insect Societies From Genome to Sociocomplexity, in eds J. Gadau and J. H. Fewell (Cambridge, MA: Harvard University Press), 74-104.

Cornwallis, C. K., West, S. A., Davis, K. E., and Griffin, A. S. (2010). Promiscuity and the evolutionary transition to complex societies. Nature 466, 969-972. doi: 10.1038/nature09335

Cosmides, L. M., and Tooby, J. (1981). Cytoplasmic inheritance and intragenomic conflict. J. Theor. Biol. 89, 83-129. doi: 10.1016/0022-5193(81)90181-8

Cronin, A. L., Molet, M., Doums, C. T. M., and Peeters, C. (2013) Recurrent evolution of dependent colony foundation across eusocial insects. Annu. Rev. Entomol. 58, 37-55. doi: 10.1146/annurev-ento-120811153643

Crozier, R. H., and Pamilo, P. (1996). Evolution of Social Insect Colonies. Oxford: Oxford University Press.

Debout, G., Schatz, B., Elias, M., and McKey, D. (2007). Polydomy in ants: what we know, what we think we know, and what remains to be done. Biol. J. Linn. Soc. 90, 319-348. doi: 10.1111/j.1095-8312.2007.00728.x

Duffy, J. E., and Macdonald, K. S. (2010). Kin structure, ecology and the evolution of social organization in shrimp: a comparative analysis. Proc. R. Soc. Lond. B Biol. Sci. 277, 575-584. doi: 10.1098/rspb. 2009.1483

Ellis, S., and Robinson, E. (2014). Polydomy in red wood ants. Insectes Soc. 61, 111-122. doi: 10.1007/s00040-013-0337-z

Fisher, R. M., Cornwallis, C. K., and West, S. A. (2013). Group formation, relatedness, and the evolution of multicellularity. Curr. Biol. 23, 1120-1125. doi: 10.1016/j.cub.2013.05.004

Folse, H. J. III, and Roughgarden, J. (2010). What is an individual organism? A multilevel selection perspective. Q. Rev. Biol. 85, 447-572. doi: 10.1086/656905

Fournier, D., Keller, L., Passera, L., and Aron, S. (2003). Colony sex ratios vary with breeding system but not relatedness asymmetry in the facultatively polygynous ant Pheidole pallidula. Evolution 57, 1336-1342. doi: 10.1111/j.0014-3820.2003.tb00341.x

Fromhage, L., and Kokko, H. (2010). Spatial seed and pollen games: dispersal, sex allocation, and the evolution of dioecy. J. Evol. Biol. 23, 1947-1956. doi: 10.1111/j.1420-9101.2010.02057.x

Gardner, A., and Grafen, A. (2009). Capturing the superorganism: a formal theory of group adaptation. J. Evol. Biol. 22, 659-671. doi: 10.1111/j.1420-9101.2008. 01681.x

Godfrey-Smith, P. (2009). Darwinian Populations and Natural Selection. Oxford: Oxford University Press. doi: 10.1093/acprof:osobl/9780199552047.001.0001

Godfrey-Smith, P. (2016). "Individuality and life-cycles," in Individuals Across the Science, eds A. Guay and T. Pradeau (Oxford, UK: Oxford University Press), 85-102.

Gordon, D. M. (2010). Ant Encounters: Interaction Networks and Colony Behavior. Princeton, NJ: Princeton University Press.

Gyllenstrand, N., and Seppä, P. (2003). Conservation genetics of the wood ant, Formica lugubris, in a fragmented landscape. Mol. Ecol. 12, 2931-2940. doi: 10.1046/j.1365-294X.2003.01975.x

Gyllenstrand, N., Seppä, P., and Pamilo, P. (2005). Restricted gene flow between two social forms in the ant Formica truncorum. J. Evol. Biol. 18, 978-984. doi: 10.1111/j.1420-9101.2005.00908.x

Heinze, J., Frohschammer, S., and Bernadou, A. (2013). Queen life-span and total reproductive success are positively associated in the ant Cardiocondyla cf. kagutsuchi. Behav. Ecol. Sociobiol. 67, 1555-1562. doi: 10.1007/s00265-0131567-9 
Heinze, J., and Keller, L. (2000). Alternative reproductive strategies: a queen perspective in ants. Trends Ecol. Evol. 15, 508-512. doi: 10.1016/S01695347(00)01995-9

Heinze, J., and Schrempf, A. (2012). Terminal investment: individual reproduction of ant queens increases with age. PLoS ONE 7:e35201. doi: 10.1371/journal. pone. 0035201

Helanterä, H., and Ratnieks, F. L. W. (2009). Sex allocation conflict in insect societies: who wins? Biol. Lett. 5, 700-704. doi: 10.1098/rsbl.2009.0501

Helanterä, H., Strassmann, J. E., Carrillo, J., and Queller, D. C. (2009). Unicolonial ants: where do they come from, what are they, and where are they going? Trends Ecol. Evol. 24, 341-349. doi: 10.1016/j.tree.2009.01.013

Helms, K. R. (1999). Colony sex ratios, conflict between queens and workers, and apparent queen control in the ant Pheidole desertorum. Evolution 53, 1470-1478. doi: 10.2307/2640893

Helms, K. R., Fewell, J. H., and Rissing, S. W. (2000). Sex ratio determination by queens and workers in the ant Pheidole desertorum. Anim. Behav. 59, 523-527. doi: 10.1006/anbe.1999.1343

Helms, K. R., Reuter, M., and Keller, L. (2005). Sex-ratio conflict between queens and workers in eusocial hymenoptera: mechanisms, costs, and the evolution of split colony sex ratios. Evolution 59, 2626-2638. doi: 10.1111/j.00143820.2005.tb00975.x

Henshaw, J. M., Marshall, D. J., Jennions, M. D., and Kokko, H. (2014). Local gamete competition explains sex allocation and fertilization strategies in the sea. Am. Nat. 184, E32-E49. doi: 10.1086/676641

Hölldobler, B., and Wilson, E. O. (2008). The Superorganism. New York, NY: WW Norton \& Company Inc.

Hughes, W. O. H., Oldroyd, B. P., Beekman, M., and Ratnieks, F. L. W. (2008). Ancestral monogamy shows kin selection is key to the evolution of eusociality. Science 320, 1213-1216. doi: 10.1126/science.1156108

Huxley, J. H. (1912). The Individual in the Animal Kingdom. Cambridge: Cambridge University Press.

Ingram, K. K., Pilko, A., Heer, J., and Gordon, D. M. (2013). Colony life history and lifetime reproductive success of red harvester ant colonies. J. Anim. Ecol. 82, 540-550. doi: 10.1111/1365-2656.12036

Jaffé, R., Garcia-Gonzalez, F., Den Boer, S., Simmons, L. W., and Baer, B. (2012). Patterns of paternity skew among polyandrous social insects: what can they tell us about the potential for sexual selection? Evolution 66, 3778-3788. doi: 10.1111/j.1558-5646.2012.01721.x

Johnson, B. R., and Linksvayer, T. A. (2010). Deconstructing the superorganism: social physiology, groundplans, and sociogenomics. Q. Rev. Biol. 85, 57-79. doi: $10.1086 / 650290$

Keller, L. (ed.). (1993). Queen Number and Sociality in Insects. Oxford: Oxford University Press.

Keller, L., and Genoud, M. (1997). Extraordinary lifespans in ants: a test of evolutionary theories of ageing. Nature 389, 958-960. doi: 10.1038/40130

Kennedy, P., Uller, T., and Helanterä, H. (2014). Are ant supercolonies crucibles of a new major transition in evolution? J. Evol. Biol. 27, 1784-1796. doi: 10.1111/ jeb.12434

Kramer, B. H., and Schaible, R. (2013). Colony size explains the lifespan differences between queens and workers in eusocial Hymenoptera. Biol. J. Linn. Soc. 109, 710-724. doi: 10.1111/bij.12072

Kümmerli, R., Helms, K. R., and Keller, L. (2005). Experimental manipulation of queen number affects colony sex ratio investment in the highly polygynous ant Formica exsecta. Proc. R. Soc. B Biol. Sci. 272, 1789-1794. doi: $10.1098 / \mathrm{rspb} .2005 .3163$

Kümmerli, R., and Keller, L. (2009). Patterns of split sex ratio in ants have multiple evolutionary causes based on different within-colony conflicts. Biol. Lett. 5, 713-716. doi: 10.1098/rsbl.2009.0295

Kupriyanova, E., Nishi, E., Ten Hove, H., and Rzhavsky, A. (2001). Life-history patterns in serpulimorph polychaetes: ecological and evolutionary perspectives. Oceanogr. Mar. Biol. Ann. Rev. 39, 1-101.

Lehtonen, J., and Kokko, H. (2011). Two roads to two sexes: unifying gamete competition and gamete limitation in a single model of anisogamy evolution. Behav. Ecol. Sociobiol. 65, 445-459. doi: 10.1007/s00265-0101116-8

Lehtonen, J., and Parker, G. A. (2014). Gamete competition, gamete limitation, and the evolution of the two sexes. Mol. Hum. Reprod. 20, 1161-1168. doi: 10.1093/ molehr/gau068
Linksvayer, T. A., Busch, J. W., and Smith, C. R. (2013). Social supergenes of superorganisms: do supergenes play important roles in social evolution? Bioessays 35, 683-689. doi: 10.1002/bies.201300038

Loope, K. J. (2015). Queen killing is linked to high worker-worker relatedness in a social wasp. Curr. Biol. 25, 2976-2979. doi: 10.1016/j.cub.2015.09.064

Lukas, D., and Clutton-Brock, T. (2012). Cooperative breeding and monogamy in mammalian societies. Proc. R. Soc. Lond. B Biol. Sci. 279, 2151-2156. doi: 10.1098/rspb.2011.2468

Maynard Smith, J., and Szathmáry, E. (1995). The Major Transitions in Evolution. Oxford, UK: Oxford University Press.

Meunier, J., West, S. A., and Chapuisat, M. (2008). Split sex ratios in the social Hymenoptera: a meta-analysis. Behav. Ecol. 19, 382-390. doi: 10.1093/beheco/arm143

Nonacs, P., and Kapheim, K. M. (2007). Social heterosis and the maintenance of genetic diversity. J. Evol. Biol. 20, 2253-2265. doi: 10.1111/j.14209101.2007.01418.x

Nonacs, P., and Tobin, J. E. (1992). Selfish larvae - development and the evolution of parasitic behavior in the hymenoptera. Evolution 46, 1605-1620. doi: $10.2307 / 2410019$

Oster, G. F., and Wilson, E. O. (1978). Caste and Ecology in the Social Insects. Princeton, NJ: Princeton University Press.

Pamilo, P., and Rosengren, R. (1983). Sex ratio strategies in Formica ants. Oikos 40, 24-35. doi: $10.2307 / 3544196$

Parker, G. A. (1978). Selection on nonrandom fusion of gametes during evolution of anisogamy. J. Theor. Biol. 73, 1-28. doi: 10.1016/0022-5193(78)90177-7

Parker, G. A. (1992). The evolution of sexual size dimorphism in fish*. J. Fish Biol. 41, 1-20. doi: 10.1111/j.1095-8649.1992.tb03864.x

Parker, G. A., Baker, R., and Smith, V. (1972). The origin and evolution of gamete dimorphism and the male-female phenomenon. J. Theor. Biol. 36, 529-553. doi: 10.1016/0022-5193(72)90007-0

Parker, G. A., and Lehtonen, J. (2014). Gamete evolution and sperm numbers: sperm competition versus sperm limitation. Proc. R. Soc. Lond. B Biol. Sci. 281:20140836. doi: 10.1098/rspb.2014.0836

Passera, L., Aron, S., Vargo, E. L., and Keller, L. (2001). Queen control of sex ratio in fire ants. Science 293, 1308-1310. doi: 10.1126/science.1062076

Pineda-Krch, M., and Lehtilä, K. (2004). Costs and benefits of genetic heterogeneity within organisms. J. Evol. Biol. 17, 1167-1177. doi: 10.1111/j.1420-9101.2004.00808.x

Queller, D. C., and Strassmann, J. E. (2009). Beyond society: the evolution of organismality. Philos. Trans. R. Soc. B Biol. Sci. 364, 3143-3155. doi: 10.1098/rstb.2009.0095

Randerson, J. P., and Hurst, L. D. (2001). The uncertain evolution of the sexes. Trends Ecol. Evol. 16, 571-579. doi: 10.1016/S0169-5347(01)02270-4

Ratnieks, F. L. W., Foster, K. R., and Wenseleers, T. (2006). Conflict resolution in insect societies. Annu. Rev. Entomol. 51, 581-608. doi: 10.1146/annurev.ento.51.110104.151003

Reuter, M., Helms, K. R., Lehmann, L., and Keller, L. (2004). Effects of brood manipulation costs on optimal sex allocation in social Hymenoptera. Am. Nat. 164, E73-E82. doi: 10.1086/422659

Robinson, G. E., Grozinger, C. M., and Whitfield, C. W. (2005). Sociogenomics: social life in molecular terms. Nat. Rev. Genet. 6, 257-270. doi: 10.1038/nrg1575

Rosengren, R., and Pamilo, P. (1983). The evolution of polygyny and polydomy in Formica ants. Ann. Zool. Fenn. 42, 65-77.

Rosengren, R., Sundström, L., and Fortelius, W. (1993). "Monogyny and polygyny in Formica ants: the result of alternative dispersal tactics," in Queen Number and Sociality in Insects, ed L. Keller (Oxford: Oxford University Press), 308-333.

Ross, K. G., Krieger, M. J. B., Shoemaker, D. D., Vargo, E. L., and Keller, L. (1997). Hierarchical analysis of genetic structure in native fire ant populations: results from three classes of molecular markers. Heredity 147, 643-655.

Ross, K. G., and Matthews, R. W. (1991). The Social Biology of Wasps. Ithaca, NY: Cornell University Press.

Ross, K. G., Shoemaker, D. D., Krieger, M. J. B., Deheer, C. J., and Keller, L. (1999). Assessing genetic structure with multiple classes of molecular markers: a case study involving the introduced fire ant Solenopsis invicta. Mol. Biol. Evol. 16, 525-543. doi: 10.1093/oxfordjournals.molbev.a026134

Ross, L., Gardner, A., Hardy, N., and West, S. A. (2013). Ecology, not the genetics of sex determination, determines who helps in eusocial populations. Curr. Biol. 23, 2383-2387. doi: 10.1016/j.cub.2013.10.013 
Rüppell, O., Heinze, J., and Hölldobler, B. (1998). Size-dimorphism in the queens of the North American ant Leptothorax rugatulus (Emery). Insect. Soc. 45, 67-77. doi: 10.1007/s000400050069

Schärer, L. (2009). Tests of sex allocation theory in simultaneously hermaphroditic animals. Evolution 63, 1377-1405. doi: 10.1111/j.1558-5646.2009.00669.x

Schrempf, A., Cremer, S., and Heinze, J. (2011). Social influence on age and reproduction: reduced lifespan and fecundity in multi-queen ant colonies. J. Evol. Biol. 24, 1455-1461. doi: 10.1111/j.1420-9101.2011. 02278.x

Schultner, E., Gardner, A., Karhunen, M., and Helanterä, H. (2014). Ant larvae as players in social conflict: relatedness and individual identity mediate cannibalism intensity. Am. Nat. 184, E161-174. doi: 10.1086/678459

Seeley, T. D. (1995). The Wisdom of the Hive. Cambridge, MA: Harvard University Press.

Seeley, T. D. (1997). Honey bee colonies are group-level adaptive units. Am. Nat. 150, S22-S41. doi: 10.1086/286048

Seppä, P., Gyllenstrand, M., Corander, J., and Pamilo, P. (2004). Coexistence of the social types: genetic population structure in the ant Formica exsecta. Evolution 58, 2462-2471. doi: 10.1111/j.0014-3820.2004.tb00875.x

Stearns, S. C. (1992). The Evolution of life Histories. Oxford: Oxford University Press.

Stearns, S. C., and Crandall, R. E. (1981). "Bet-hedging and persistence as adaptations of colonizers," in Evolution Today, eds G. G. Scudder and J. L. Reveal (Philadelphia, PA: Hunt Institute), 371-383.

Steiner, F. M., Schlick-Steiner, B. C., Konrad, H., Moder, K., Christian, E., Seifert, B., et al. (2006). No sympatric speciation here: multiple data sources show that the ant Myrmica microrubra is not a separate species but an alternate reproductive morph of Myrmica rubra. J. Evol. Biol. 19, 777-787. doi: 10.1111/j.1420-9101.2005.01053.x

Strassmann, J. E., and Queller, D. C. (2007). Insect societies as divided organisms: the complexities of purpose and cross-purpose. Proc. Natl. Acad. Sci. U.S.A. 104, 8619-8626. doi: 10.1073/pnas.0701285104

Strathmann, R., and Strathmann, M. (1982). The relationship between adult size and brooding in marine invertebrates. Am. Nat. 119, 91-101. doi: 10.1086/ 283892

Sundström, L., Chapuisat, M., and Keller, L. (1996). Conditional manipulation of sex ratios by ant workers: a test of kin selection theory. Science 274, 993-995. doi: $10.1126 /$ science.274.5289.993
Sundström, L., Keller, L., and Chapuisat, M. (2003). Inbreeding and sexbiased gene flow in the ant Formica exsecta. Evolution 57, 1552-1561. doi: 10.1111/j.0014-3820.2003.tb00363.x

Sundström, L., Seppä, P., and Pamilo, P. (2005). Genetic population structure and dispersal patterns in Formica ants - a review. Ann. Zool. Fenn. 42, 163-177.

Trivers, R. L., and Hare, H. (1976). Haplodiploidy and evolution of social insects. Science 191, 249-263. doi: 10.1126/science.1108197

Tschinkel, W. R. (1991). Insect sociometry, a field in search of data. Insect. Soc. 38, 77-82. doi: 10.1007/BF01242715

Tuomi, J., and Vuorisalo, T. (1989). What are the units of selection in modular organisms? Oikos 54, 227-233. doi: 10.2307/3565271

Weismann, A. (1893). The all-sufficiency of natural selection. Contemp. Rev. 64, 309-338.

Wenseleers, T., and Ratnieks, F. L. W. (2006). Comparative analysis of worker reproduction and policing in eusocial Hymenoptera supports relatedness theory. Am. Nat. 168, E163-E179. doi: 10.1086/508619

West, S. A. (2009). Sex Allocation. Princeton, NJ: Princeton University Press. doi: $10.1515 / 9781400832019$

West, S. A., Murray, M. G., Machado, C. A., Griffin, A. S., and Herre, E. A. (2001). Testing Hamilton's rule with competition between relatives. Nature 409, 510-513. doi: 10.1038/35054057

Wheeler, W. M. (1911). The ant colony as an organism. J. Morphol. 22, 307-325. doi: 10.1002/jmor.1050220206

Wiernasz, D. C., and Cole, B. J. (2009). Dioecy and the evolution of sex ratios in ants. Proc. R. Soc. Lond. B Biol. Sci. 276, 2125-2132. doi: 10.1098/rspb.2009.0047

Wilson, D. S., and Sober, E. (1989). Reviving the superorganism. J. Theor. Biol. 136, 337-356. doi: 10.1016/S0022-5193(89)80169-9

Conflict of Interest Statement: The author declares that the research was conducted in the absence of any commercial or financial relationships that could be construed as a potential conflict of interest.

Copyright $\odot 2016$ Helanterä. This is an open-access article distributed under the terms of the Creative Commons Attribution License (CC BY). The use, distribution or reproduction in other forums is permitted, provided the original author(s) or licensor are credited and that the original publication in this journal is cited, in accordance with accepted academic practice. No use, distribution or reproduction is permitted which does not comply with these terms. 